\title{
Rate-Dependent Compressive Behavior of Unidirectional Carbon Fiber Composites
}

\author{
AMIT G. SALVI and ANTHONY M. WAAS \\ Composite Structures Laboratory \\ Department of Aerospace Engineering \\ University of Michigan \\ Ann Arbor, MI 48109-2140 \\ ARI CALISKAN \\ Ford Motor Company \\ Safety $R$ and D Dept. \\ 1201 Village Drive \\ Dearborn, MI 48121
}

\begin{abstract}
Unidirectional carbon fiber stitched composites were subjected to off-axis compression under static and low-velocity impact loading. Specimens were cut such that the fibers were at angles of $15^{\circ}, 30^{\circ}, 45^{\circ}$ and $60^{\circ}$ to the direction of loading. A modified compression fixture was used to carry out the tests. Static tests were carried out on a hydraulically activated MTS loading frame, where specimens were subjected to displacement controlled loading. Low-velocity impact tests were conducted on a drop tower facility. A three-strain-gauge rosette was used to measure global strains. Load was measured using a load cell. Owing to the unique microstructure of the specimens, a modified three-parameter characterization of the inelastic response was used, and the constants associated with this characterization were determined uniquely. Independently, Iosipescu shear tests were carried out to determine the shear response of the material under static and low-velocity impact conditions. The shear response so determined was checked against the off-axis test results. It is shown that rate-dependent interfacial effects are predominant in these materials. Polym. Compos. 25:397-406, 2004. ๑ 2004 Society of Plastics Engineers.
\end{abstract}

\section{INTRODUCTION}

$\mathrm{T}$ he ultimate strength and toughness of a composite material are indication of its ability to absorb energy when subjected to crush loads, either applied slowly (statically) or within a short duration (quasi-statically or dynamically). Because braided and fabric composite structures contain a well-defined microstructure, both the ultimate strength and toughness can be related to micro-structural variables. In turn, these micro-structural features and their behavior are reflected at the macro level. For example, the rate sensitivity of the matrix and the rate sensitivity of the fiber/matrix interface can contribute to the overall rate sensitivity of a composite material at the macroscopic level.

Previous work ${ }^{1}$ (Salvi and Waas, 2002) using glass fiber-reinforced braided textile composite tubes has

(C) 2004 Society of Plastics Engineers

Published online in Wiley InterScience (www.interscience.wiley.com). DOI: $10.1002 /$ pc. 20033 revealed the following important observations with respect to energy absorption. Compressive crush tests were carried out on $\left[0^{\circ} / \pm 30^{\circ}\right]$ braided fabric square cross-section tubes at static and impact velocities in the range of 3 to $10 \mathrm{~m} / \mathrm{sec}$. For this range of impact velocity, it was observed that the crush velocity remains fairly constant during the crush process. ${ }^{2}$ The constant velocity was achieved by using a high kinetic energy of impact. The resin used for the tubes is slightly rate sensitive and is stiffer and stronger under dynamic conditions. Yet, the dynamically crushed tubes consistently absorb less energy than the statically crushed tubes, always at a lower mean "plateau" load.

Motivated by the above findings, an experimental investigation was carried out to examine the synergy between local fiber orientation and rate dependency of

\footnotetext{
${ }^{1}$ Automotive composite Consortium, energy management work group.

${ }^{2}$ This is an assumption. In general, strain gauges placed on the specimen surface during the test show that strain rate is not constant but changes throughout the loading process.
} 
the matrix. Even though a braided tube is crushed axially, the tube wall material, locally, has fibers aligned at an angle to the direction of the applied load. Thus, in a local coordinate system, which is aligned along the local fiber tow direction, the state of stress involves axial compression, transverse compression, and shear. The local axial compression is borne by the fiber tows while the matrix layers between any two fiber tows are subjected to a combination of transverse compression and shear. The fiber/matrix interface is also subjected to a combined transverse compression and shear.

A large amount of experimental and analytical work has been reported pertaining to the inelastic characterization of prepreg-based laminated composites, under static and dynamic conditions, by Sun and co-workers $(1-10)$ and by Hsiao et al. $(11-13)$. Based on their experimental data, Sun and Chen (1) proposed a convenient one-parameter flow rule for orthotropic plasticity that has been widely used as an inelastic response model for prepreg-based laminated unidirectional fiber-reinforced composite materials.

The focus of the present work is the compressive response of tow-reinforced stitched unidirectional composites under static, quasi-static, and low-velocity impact conditions. Because of the unique microstructure of this material, a three-parameter material characterization of the inelastic response has been adopted to account for in-plane local transverse compression, shear, axial compression (along the fiber tows due to unintended local fiber misalignments), and coupling between axial and transverse compression, which are all present during off-axis compression. In addition, it is shown that the response of the fiber tow/matrix interface during an off-axis test cannot be inferred from tests that characterize the interface under simple shear alone or transverse compression alone. This nonlinear behavior of the interface is found to play an important role in the inelastic response of the composite.

\section{MATERIAL DESCRIPTION}

Unidirectional stitched carbon fiber textile composites were used for this study. Fibers are stitched together in bundles to form fiber tows. Approximately 80,000 fibers were bundled in one tow. The fiber tows are subsequently stitched together to form a unidirectional fiber mat. Ten such fiber mats are stacked together and vinyl ester resin (Ashland Hetron 922) is infused in preparation for liquid moldings. When the matrix is infused between flat platens that hold the fiber mats, the cross sections of the fiber tows become oval in shape. Pockets of the matrix are seen in between fiber tows. Matrix is also present within a fiber tow. This gives the resulting material a unique microstructure as shown in Fig. 1.

\section{SPECIMEN GEOMETRY}

Rectangular off-axis specimens of size $38.1 \times 209.55$ $\mathrm{mm}(1.5 \times 8.25$ inches) were cut from a unidirectional plaque. The specimens were cut in such a way that the fibers make angles of $15^{\circ}, 30^{\circ}, 45^{\circ}$, and $60^{\circ}$ to the direction of loading. The loading surfaces of the specimen were cut in such a way that they maintain close parallelism. Iosipescu shear specimens, $76.2 \times 25.4 \mathrm{~mm}$ $(3 \times 1$ inch) long with a $12.7-\mathrm{mm}$ (0.5-inch)-wide notch in the center were cut. The dimensions of the test specimens are described in Fig. 2. The Iosipescu test specimens were cut at fiber angles of $0^{\circ}$ and $90^{\circ}$ with

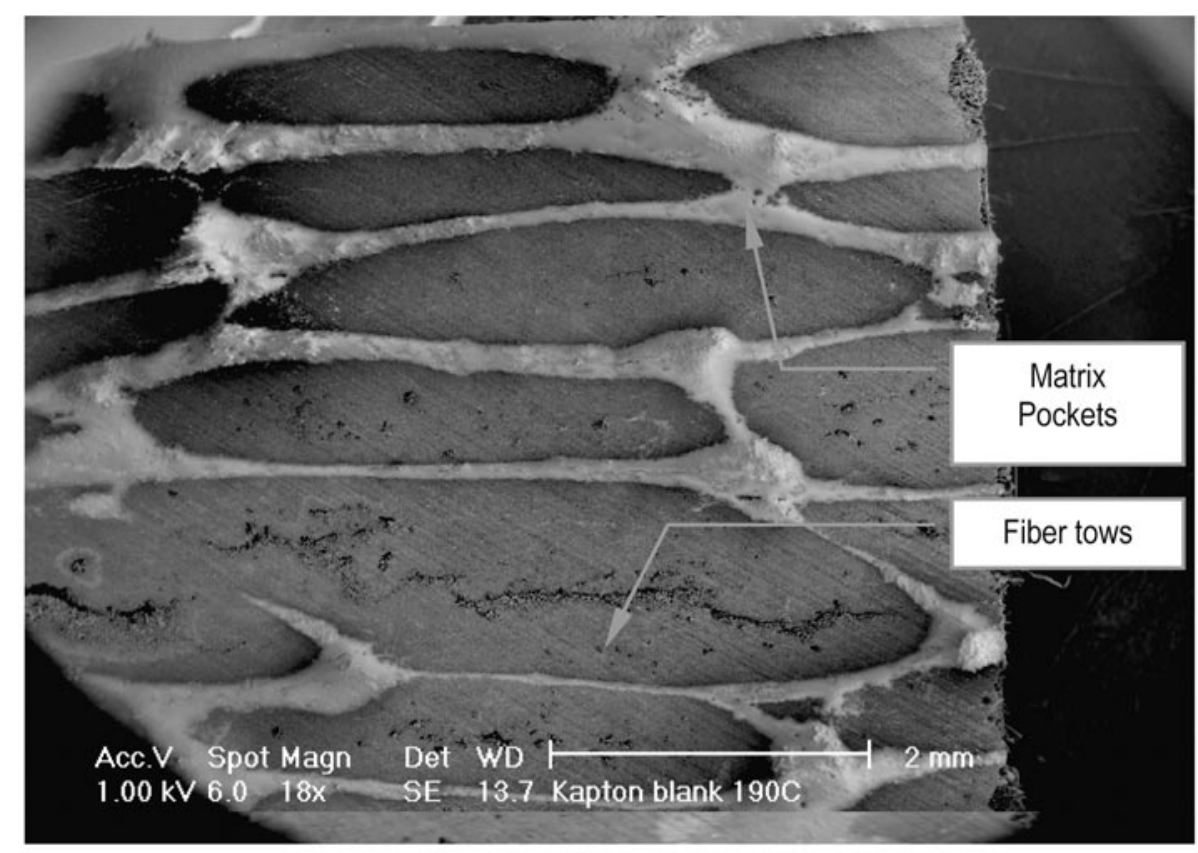

Fig. 1. Cross section of the specimen. 
respect to the direction of loading. These configurations give both a direct and an indirect measure of shear load transfer between fiber tows and matrix.

\section{EXPERIMENTAL PROCEDURE}

Off-axis compression tests were carried out by using a compression fixture as shown in Fig. 3a. Anti-buckling guide supports on the specimen sides were used to prevent global buckling of the specimens. The specimens were slotted between the compression fixture and the top loading head, which maintains a uniform contact along the width of the specimen. The bottom edge of the specimen was slotted into a groove, which was filled with Devcon putty providing a "rigidly" fixed support at the edge away from the loading edge. The loading frame actuator motion of $0.005 \mathrm{~mm} / \mathrm{sec}$ was applied to the top loading head of the compression fixture. Load was measured by a load cell mounted on the actuator of the MTS loading frame. A three-strain-gauge rosette was placed in the center of the specimen to measure the global strain state in the specimen. Backto-back strain gauges were used to check for planarity of the specimen response and it was deemed that bending was insignificant.

Quasi-static compression tests were carried out on a MTS loading frame at an actuator speed of $50.8 \mathrm{~mm} /$ sec, while low-velocity impact (LVI) compression tests were carried out on a drop tower. For the LVI tests, a dead weight of approximately $43 \mathrm{~kg}$ was dropped on the loading head of the compression fixture. Load was

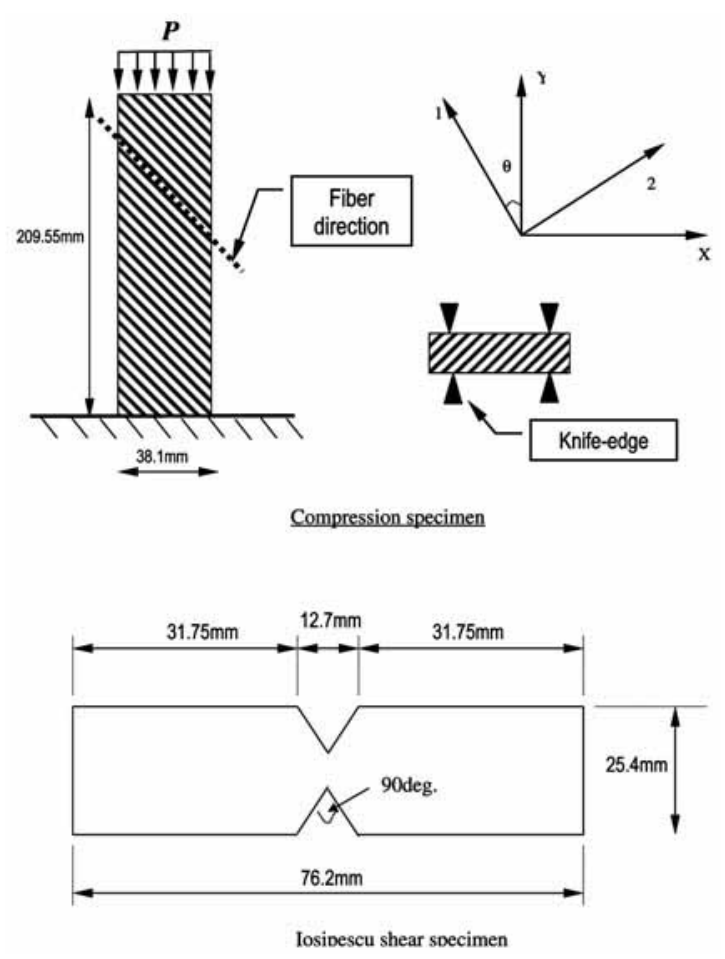

Fig. 2. Dimensions of the specimens.

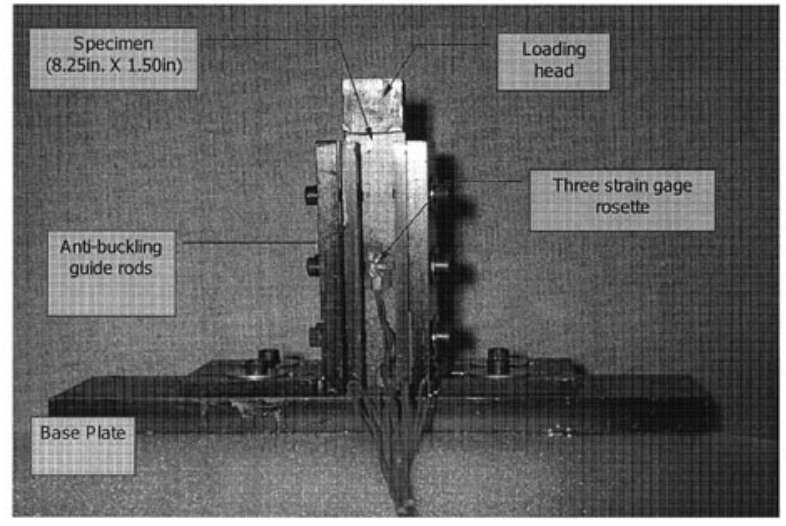

Fig. 3a. Off-axis compression fixture.

measured via a Kistler brand impact load cell placed in the impactor of the drop tower.

Iosipescu shear tests (see Ref. 14) were carried out using an Iosipescu shear fixture as shown in Fig. $3 b$. The loading frame actuator motion of $0.005 \mathrm{~mm} / \mathrm{sec}$ was applied to the moving grip of the Iosipescu shear fixture. Load was measured by a load cell mounted on the actuator of the MTS loading frame. A three-straingauge rosette was placed in the notch area to measure the strain state in the specimen. Quasi-static Iosipescu shear tests were carried out with an actuator velocity of $50.80 \mathrm{~mm} / \mathrm{sec}$ on an MTS loading frame, while LVI Iosipescu tests were carried out on a drop tower.

In this paper, an average strain rate is defined as

$$
\dot{\varepsilon}_{\text {avg }}^{\text {axial }}=\frac{1}{T} \int_{0}^{T_{d}} \varepsilon_{y}(\eta) d \eta
$$

where $T_{d}$, as shown in Fig. 4 , is the duration over which data is acquired. That is, at $t=T_{d}$ the specimen fails. Thus, strain rate refers to the values given by $E q 1$.

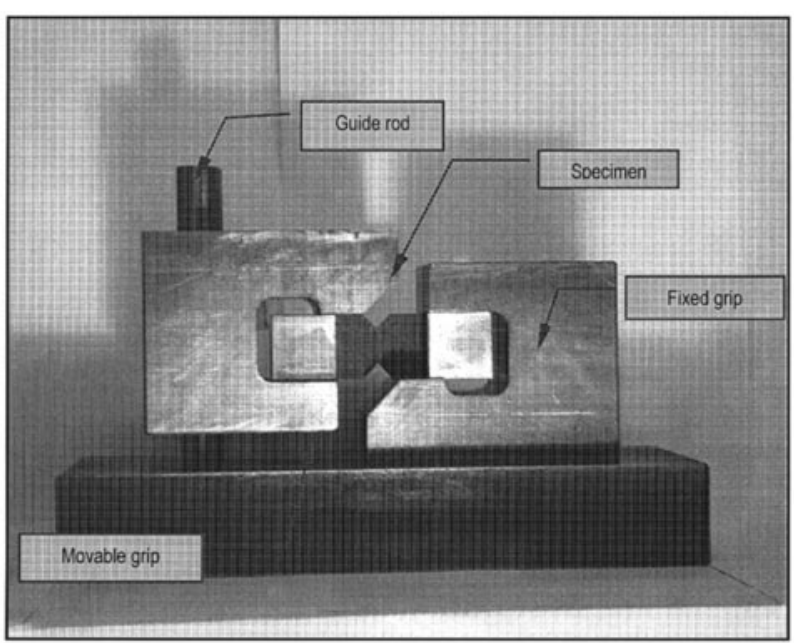

Fig. 3b. Iosipescu shear fixture. 


\section{ANALYSIS OF THE DATA}

In the off-axis test, load and global strains for every test are measured in order to calculate local stress and strain state as shown below. From the figure of an isolated infinitesimal element in the principal material coordinate system,
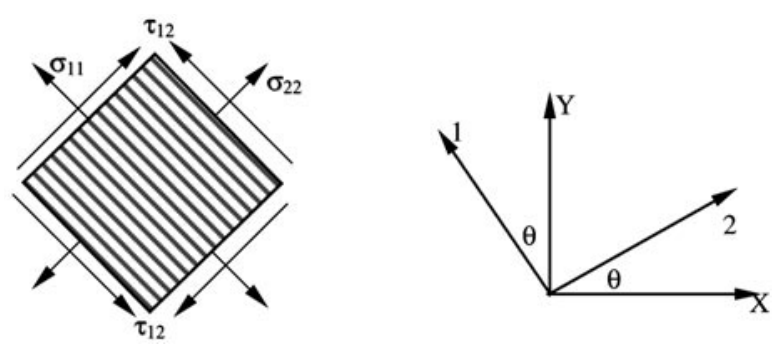

$$
\begin{gathered}
\sigma_{11}=-\sigma_{y} \cdot \cos ^{2} \theta \\
\sigma_{22}=-\sigma_{y} \cdot \sin ^{2} \theta \\
\tau_{12}=-\sigma_{y} \cdot \sin \theta \cdot \cos \theta
\end{gathered}
$$

and

$$
\begin{gathered}
\varepsilon_{11}=\left(\frac{\varepsilon_{x}+\varepsilon_{y}}{2}\right)-\left(\frac{\varepsilon_{x}-\varepsilon_{y}}{2}\right) \cos 2 \theta-\frac{\gamma_{x y}}{2} \sin 2 \theta \\
\varepsilon_{22}=\left(\frac{\varepsilon_{x}+\varepsilon_{y}}{2}\right)+\left(\frac{\varepsilon_{x}-\varepsilon_{y}}{2}\right) \cos 2 \theta+\frac{\gamma_{x y}}{2} \sin 2 \theta \\
\gamma_{12}=\left(\varepsilon_{y}-\varepsilon_{x}\right) \sin 2 \theta+\gamma_{x y} \cos 2 \theta
\end{gathered}
$$

An orthotropic yield function or plastic potential that is quadratic in stresses for a $3 \mathrm{D}$ composite is

$$
\begin{aligned}
& 2 f\left(\sigma_{i j}\right)=a_{11} \sigma_{11}^{2}+a_{22} \sigma_{22}^{2}+a_{33} \sigma_{33}^{2}+2 a_{12} \sigma_{11} \sigma_{22}+ \\
& 2 a_{13} \sigma_{11} \sigma_{33}+2 a_{23} \sigma_{22} \sigma_{33}+2 a_{44} \sigma_{23}{ }^{2}+2 a_{55} \sigma_{13}{ }^{2}+2 a_{66} \sigma_{12}^{2}
\end{aligned}
$$

Considering planar $(1-2)$ stresses, the above relation reduces to

$$
2 f\left(\sigma_{i j}\right)=a_{11} \sigma_{11}^{2}+a_{22} \sigma_{22}^{2}+2 a_{12} \sigma_{11} \sigma_{22}+2 a_{66} \sigma_{12}^{2}
$$

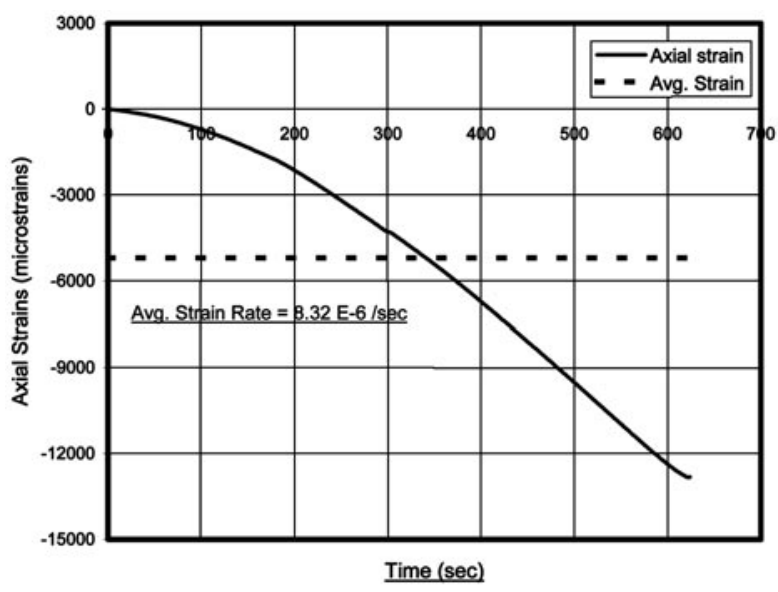

Fig. 4. Average axial strain rate for static test.
Thus, equivalent stress and equivalent strain are defined as

$\bar{\sigma}=\left[\frac{3}{2}\left(a_{11} \sigma_{11}^{2}+a_{22} \sigma_{22}^{2}+2 a_{12} \sigma_{11} \sigma_{22}+2 a_{66} \sigma_{12}^{2}\right)\right]^{1 / 2}$

$a_{22}$ is set to 1 without loss of generality.

An equivalent stress and a work conjugate equivalent plastic strain are defined as,

$$
\begin{gathered}
\bar{\sigma}=\left[\frac{3}{2}\left(a_{11} \sigma_{11}^{2}+a_{22} \sigma_{22}^{2}+2 a_{12} \sigma_{11} \sigma_{22}+2 a_{66} \sigma_{12}^{2}\right)\right] \\
d \varepsilon^{\bar{p}}=\left[\frac{2}{3}\left(a_{11} \sigma_{11}^{2}+a_{22} \sigma_{22}^{2}+2 a_{12} \sigma_{11} \sigma_{22}+2 a_{66} \sigma_{12}^{2}\right)\right] d \lambda, \\
d \lambda=\frac{3}{2}\left(\frac{d \varepsilon^{\bar{p}}}{d \bar{\sigma}}\right)\left(\frac{d \bar{\sigma}}{\bar{\sigma}}\right)
\end{gathered}
$$

Substituting $E q 2$ into $E q$ 5, the following is obtained.

$$
\bar{\sigma}=\left[\frac { 3 } { 2 } \left(a_{11} \cdot \sigma_{y}^{2} m^{4}+\sigma_{y}^{2} n^{4}+2 a_{12} \cdot \sigma_{y}^{2} m^{2} n^{2}+\right.\right.
$$

$$
\left.\left.2 a_{66} \cdot \sigma_{y}^{2} m^{2} n^{2}\right)\right]^{1 / 2}
$$

$$
\begin{gathered}
\text { or } \\
\bar{\sigma}=\sigma_{y} \cdot h(\theta)
\end{gathered}
$$

similary,

$$
\bar{\varepsilon}^{p}=\varepsilon^{p} / h(\theta)
$$

where

$$
\begin{aligned}
m & =\cos \theta \\
n & =\sin \theta
\end{aligned}
$$

$$
h(\theta)=\left[\frac{3}{2}\left(a_{11} m^{4}+n^{4}+2 a_{12} m^{2} n^{2}+2 a_{66} m^{2} n^{2}\right)\right]^{1 / 2}
$$

When $E q 6$ is specialized to a case of simple shear, $\bar{\sigma}$ and $\bar{\varepsilon}^{p}$ are reduced to,

$$
\begin{gathered}
\bar{\sigma}=\tau_{12} \sqrt{3 a_{66}} \\
\bar{\varepsilon}^{p}=\frac{\gamma_{12}^{p}}{\sqrt{3 a_{66}}}
\end{gathered}
$$

Thus, by measuring $\sigma_{y}$ and $\varepsilon_{y}$ in the off-axis test, the equivalent stress and equivalent plastic strain are plotted for static, quasi-static and LVI cases. For each test, values of $a_{11}, a_{12}$ and $a_{66}$ are selected such that the curves of equivalent stress vs. equivalent plastic strain for each off-axis angle collapse to one curve. This master curve can then be used to characterize material response under very general planar multiaxial stress states. In Salvi et al. (15), the equivalent plastic strain $\bar{\varepsilon}$ is approximated as $\bar{\varepsilon}^{p}=A(\bar{\sigma})^{n}$, and a plot of $A$ and $n$ as a function of strain rate is given. It was found that for all practical purposes, $n$, the power law index was independent of strain rate for the range of strain rates examined. The values of $A$ and $n$ as obtained for the present material are given in Table 3. 
Fig. 5. Equivalent stress vs. equivalent plastic strain.

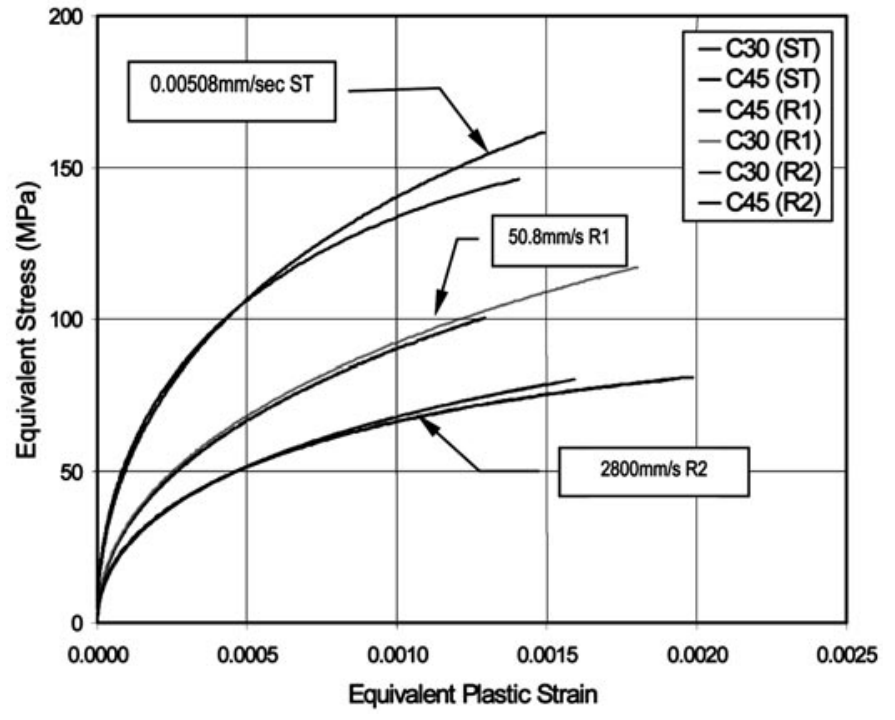

The material was assumed to be homogenous and orthotropic.

The following elastic properties were used in the FE model

$$
\begin{aligned}
& E_{\text {fiber }}=227.527 \mathrm{GPa}, \quad \nu_{\text {fiber }}=0.20 \\
& E_{\text {matrix }}=3.998 \mathrm{GPa}, \quad \nu_{\text {fiber }}=0.35 \\
& \text { Volume Fraction }\left(V_{f}\right)=0.55
\end{aligned}
$$

A very fine mesh was used around the notch area and convergence of the results was checked by varying the mesh density. The FE mesh used is shown in Fig. $8 a$ and shear stress contour plots $\left(0^{\circ}-\right.$ Case $\mathrm{A}$ and $90^{\circ}-$ Case B) are shown in Fig. 8b. A comparison of the shear

Table 1. Values of $a_{11}, a_{12}$ and $a_{66}$ Under Static and Quasi-Static Conditions.

\begin{tabular}{llccc}
\hline \multicolumn{1}{c}{ Test } & $\begin{array}{c}\text { Average } \\
\text { Strain Rate }\end{array}$ & $\boldsymbol{a}_{\mathbf{1 1}}$ & $\boldsymbol{a}_{\mathbf{1 2}}$ & $\boldsymbol{a}_{\mathbf{6 6}}$ \\
\hline $0.00508 \mathrm{~mm} / \mathrm{sec}$ & $8.32 \mathrm{E}-6 / \mathrm{sec}$ & 2.00 & 0.005 & 1.50 \\
$50.8 \mathrm{~mm} / \mathrm{sec}$ & $1.03 \mathrm{E}-1 / \mathrm{sec}$ & 1.10 & 0.020 & 0.30 \\
$2800 \mathrm{~mm} / \mathrm{sec}$ & $1.83 \mathrm{E} 0 / \mathrm{sec}$ & 0.10 & 0.100 & 0.06 \\
\hline
\end{tabular}

Table 2. Values of $\boldsymbol{A}$ and $\boldsymbol{n}$ Obtained Using Power Law.

\begin{tabular}{llcc}
\hline $\begin{array}{c}\text { Test (Impact } \\
\text { Velocity) }\end{array}$ & $\begin{array}{c}\text { Average } \\
\text { Strain Rate }\end{array}$ & $\boldsymbol{A}$ & $\boldsymbol{n}$ \\
\hline $0.00508 \mathrm{~mm} / \mathrm{sec}$ & $8.32 \mathrm{E}-6 / \mathrm{sec}$ & $1.93 \times 10^{-8}$ & 2.16 \\
$50.8 \mathrm{~mm} / \mathrm{sec}$ & $1.03 \mathrm{E}-1 / \mathrm{sec}$ & $5.62 \times 10^{-8}$ & 2.18 \\
$2800 \mathrm{~mm} / \mathrm{sec}$ & $1.83 \mathrm{E} 0 / \mathrm{sec}$ & $8.36 \times 10^{-8}$ & 2.22 \\
\hline
\end{tabular}

Table 3. Values of Shear Modulus $\left(G_{12}\right)$ Under Static and Quasi-Static Conditions.

\begin{tabular}{llcc}
\hline \multicolumn{1}{c}{ Test } & $\begin{array}{c}\text { Average } \\
\text { Strain Rate }\end{array}$ & $\begin{array}{c}\mathbf{G}_{\mathbf{1 2}} \text { (Zero) } \\
(\mathbf{G P a})\end{array}$ & $\begin{array}{c}\mathbf{G}_{\mathbf{1 2}} \mathbf{( 9 0 )} \\
(\mathbf{G P a})\end{array}$ \\
\hline $0.00508 \mathrm{~mm} / \mathrm{sec}$ & $8.32 \mathrm{E}-6 / \mathrm{sec}$ & 2.89 & 4.30 \\
$50.8 \mathrm{~mm} / \mathrm{sec}$ & $1.03 \mathrm{E}-1 / \mathrm{sec}$ & 3.19 & 4.97 \\
$2800 \mathrm{~mm} / \mathrm{sec}$ & $1.83 \mathrm{E} 0 / \mathrm{sec}$ & 3.32 & 5.74 \\
\hline
\end{tabular}


Fig. 6. Shear stress vs. plastic shear strain derived from equivalent stress vs. equivalent plastic strain.

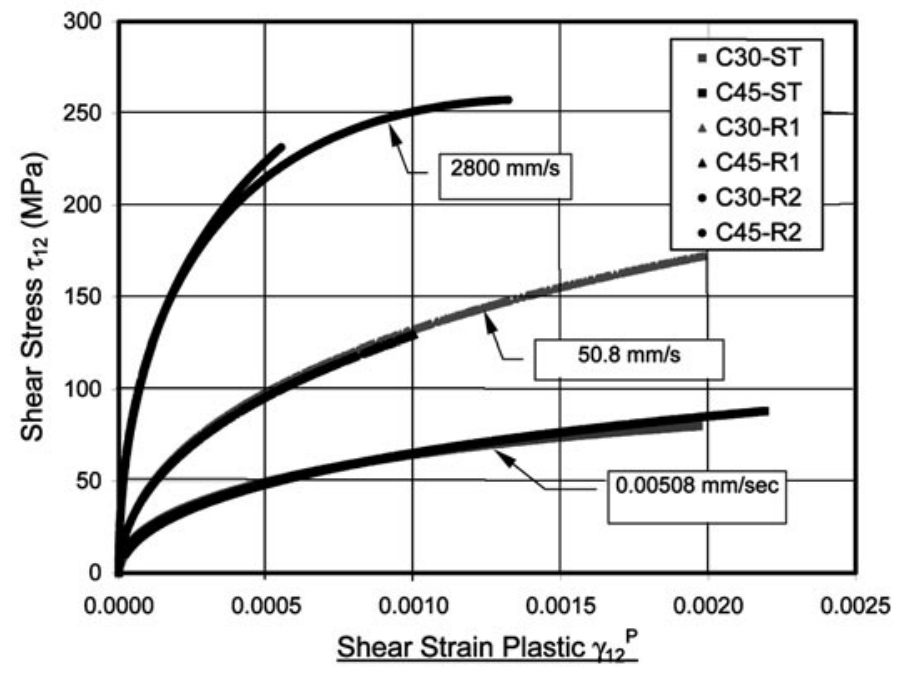

the plastic deformation, which is precursor to the failure) was different for different off-axis angle tests, i.e., mode of failure for $15^{\circ}$ test is different from that of the $60^{\circ}$ test. It is observed that under dynamic conditions, the mode of deformation depends on the material response, which is dictated by the off-axis angle of the specimen.

\section{Small angles $\left(15^{\circ}\right)$ :}

Figure $9 a$ shows a $15^{\circ}$ specimen after the test. It can be seen that for small angles the specimen fails predominantly because of planar shear between fiber tows and matrix.

\section{Intermediate angles $\left(30^{\circ}\right.$ and $\left.45^{\circ}\right)$ :}

Figure $9 b$ shows a cross section of $45^{\circ}$ specimens. Since no single component of stress (axial compression, transverse compression and shear) is dominant, planar deformation occurs in some range. Eventual failure is due to:

- Interfacial shear between tows $\rightarrow$ as the angle increases primary mode of failure shifts from interfacial shear to transverse compression.

- Transverse compression $\rightarrow$ small amount of transverse compression in and out-of-plane $(\mathrm{X}-\mathrm{Y})$ is observed. For higher impact velocities, out-of-plane (along $\mathrm{X}-\mathrm{Z}$ plane or through the thickness) failure is observed.

Similar modes of failure were observed for $30^{\circ}$ specimens. Hence convergence for equivalent stress and equivalent plastic strain was obtained for $30^{\circ}$ and $45^{\circ}$ off-axis test specimens.

\section{Large angles $\left(60^{\circ}\right)$ :}

Figure $9 c$ shows failure mode for large angled specimens. A large amount of out-of-plane or transverse tow buckling and out-of-plane splitting is observed. A cross section of the specimen clearly shows the out-of-plane splitting of the tows in a row. Eventual failure mode is observed to be: 


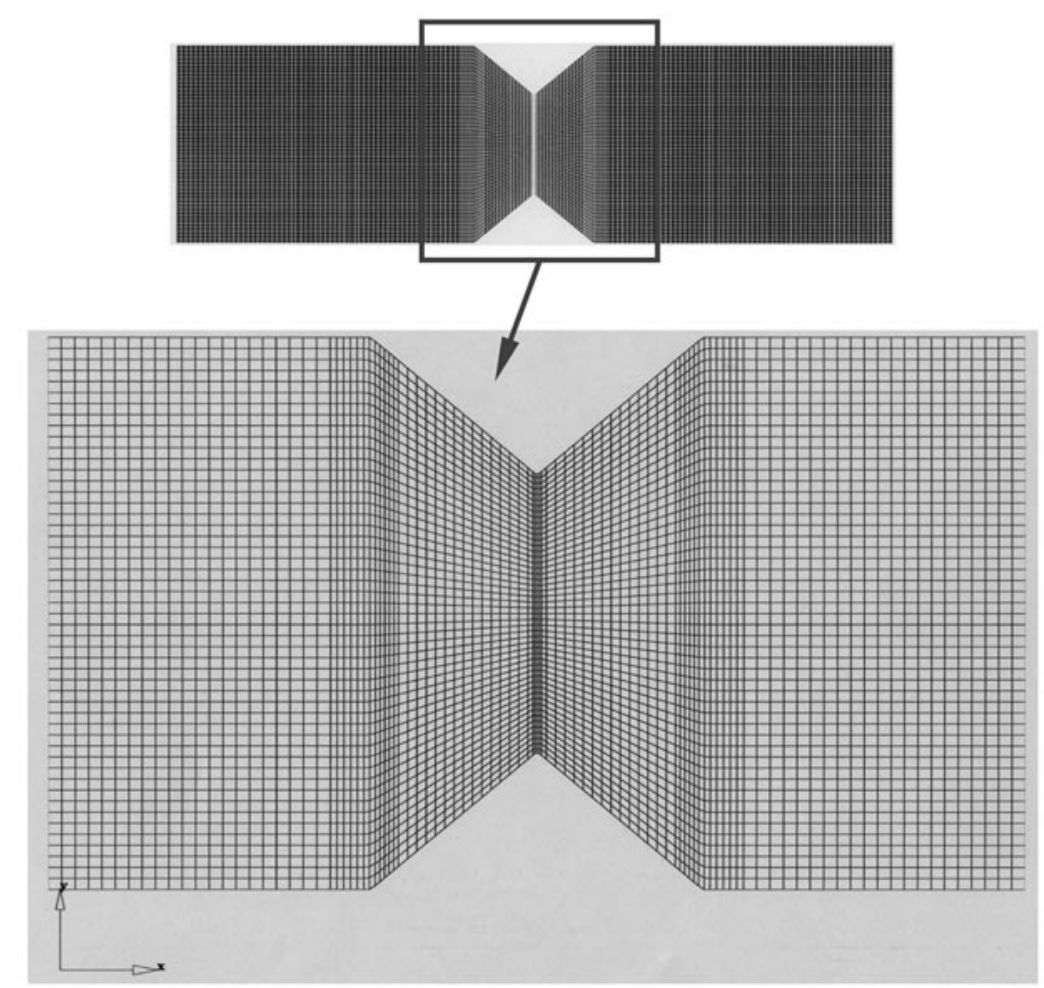

Fig. 8a. FE mesh of Iosipescu shear test specimen.
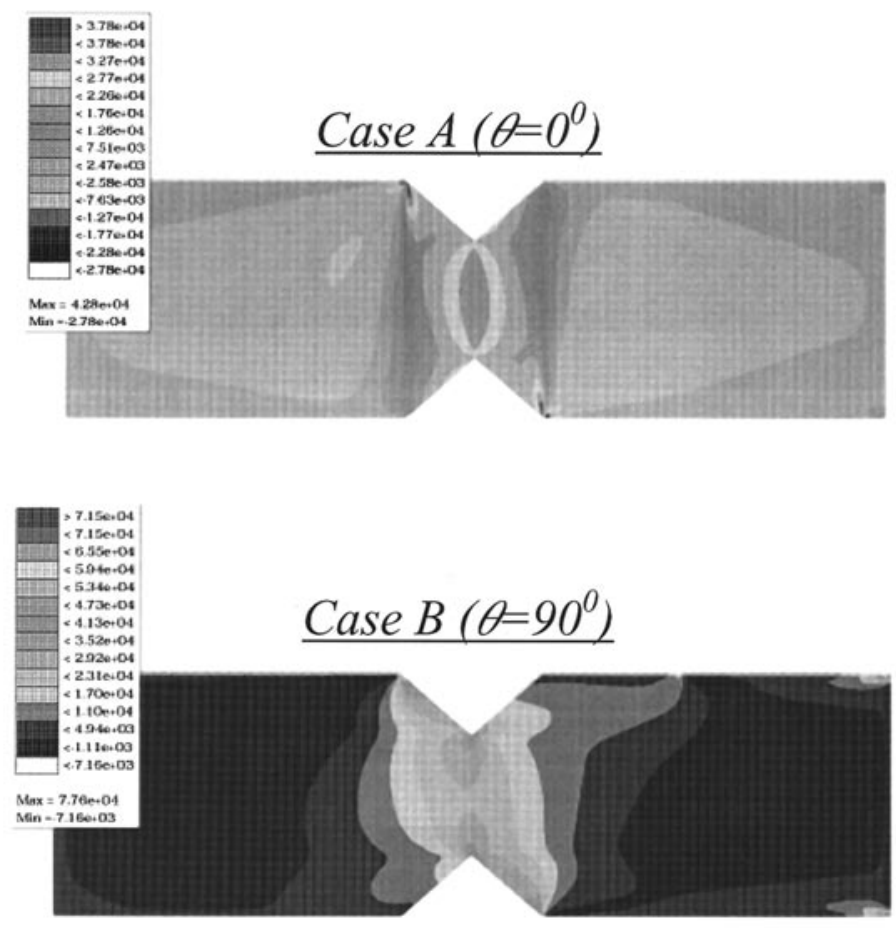

Fig. 8b. Shear stress contour plots obtained by Iosipescu FE model. 
Case $\mathrm{A}($ Factor $=1.05)$

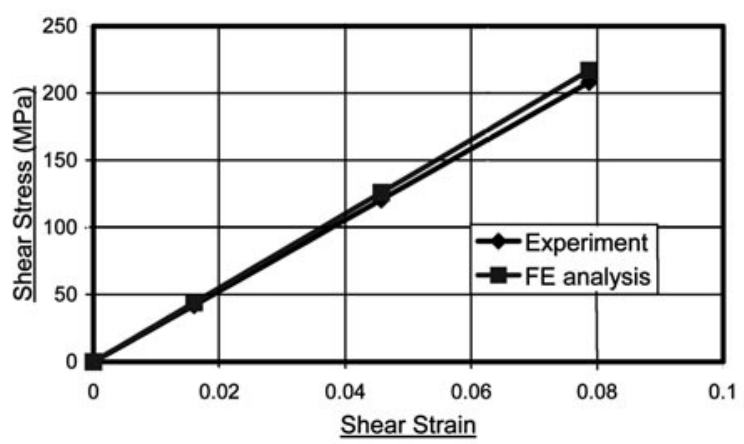

Case B (Factor $=0.82)$

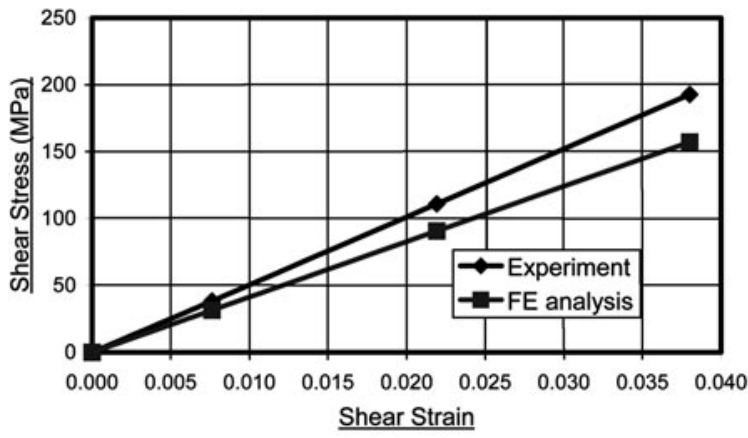

Fig. 8c. Shear stress-shear strain plot of case A and case B.
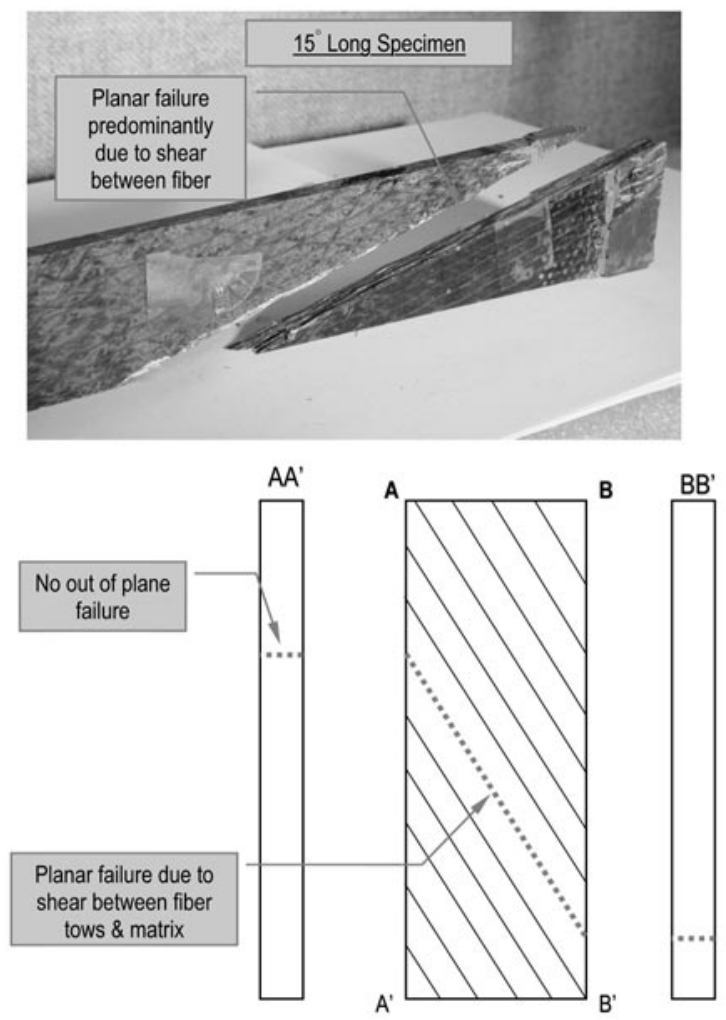

Fig. 9a. Failure mode-Small angles (15).
- In plane $(\mathrm{X}-\mathrm{Y})$ transverse compression $\rightarrow$ due to a large amount of transverse compression, fiber tows tend to buckle and pop out-of-plane. Simultaneously, owing to failure and slope along the tow length, specimen tends to slide in the $\mathrm{X}-\mathrm{Y}$ plane.

- For higher impact velocities, the out-of-plane failure is catastrophic. The formation of one or more "wedge and socket" regions due to the microstructure of the specimen is visible in Fig. 9c.

\section{DISCUSSION}

Shear stress $\left(\tau_{12}\right)$ vs. plastic shear strain $\left(\gamma^{p}{ }_{12}\right)$ behavior of this material under multiaxial stress state can be derived from $\mathrm{Eq} 6$ as follows

$$
\begin{aligned}
\tau_{12} & =\frac{\bar{\sigma}}{\sqrt{3 a_{66}}} \\
\gamma_{12}^{p} & =\bar{\varepsilon}^{p} \sqrt{3 a_{66}}
\end{aligned}
$$

Figure 6 shows the rate-dependent behavior of shear stress vs. plastic shear strain derived from the ratedependent equivalent stress vs. equivalent plastic strain using the corresponding values of $a_{66}$. The ratedependent shear behavior of the material shows a stiffening effect even though the overall equivalent behavior shows a softening trend with increasing loading rate. This trend is consistent with the Iosipescu shear rate-dependent behavior obtained from the tests
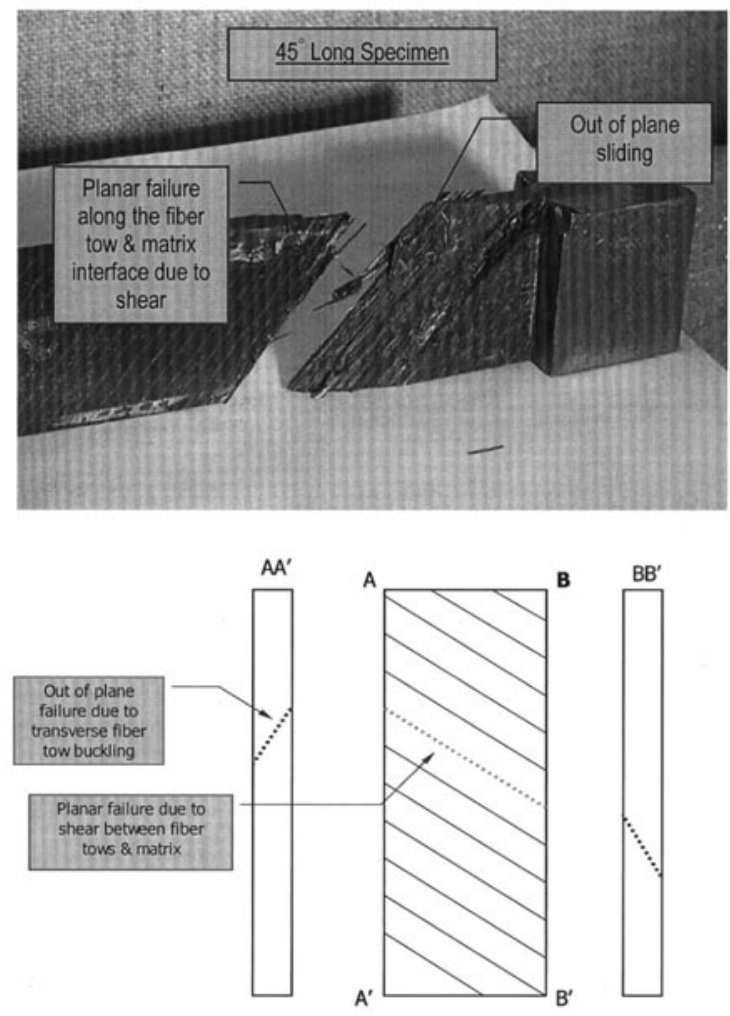

Fig. 9b. Failure mode-Intermediate angles $\left(30^{\circ}\right.$ and $\left.45^{\circ}\right)$. 


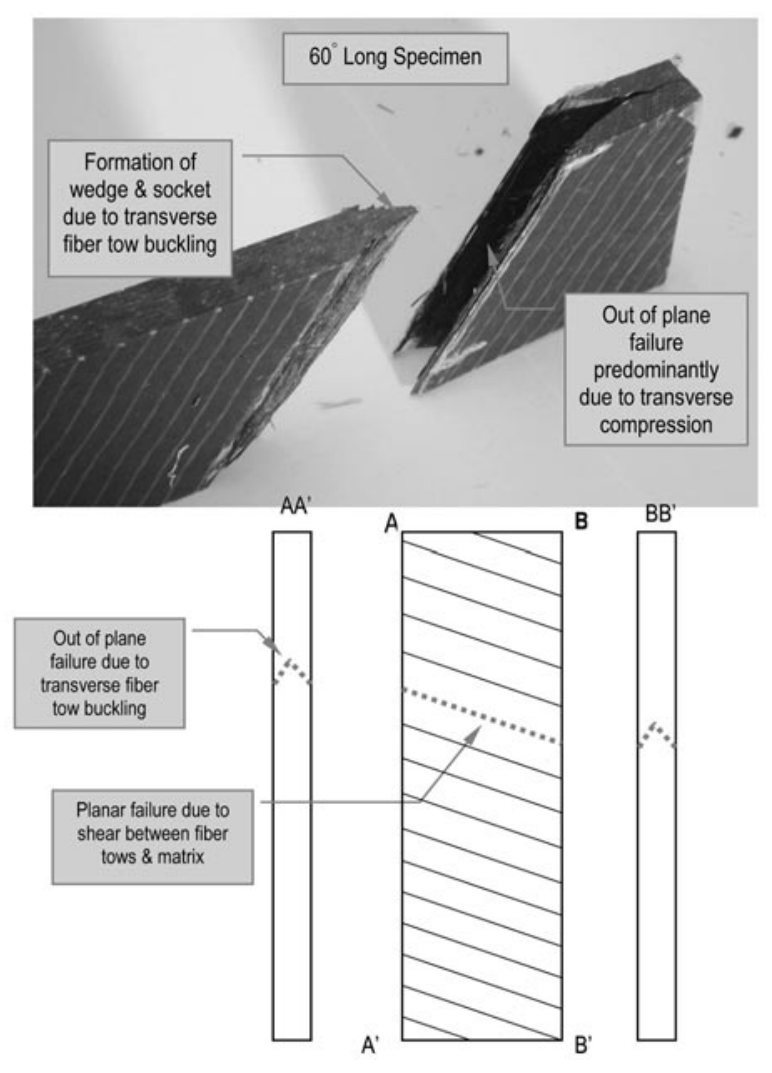

Fig. 9c. Failure mode-Large angles $\left(60^{\circ}\right)$.

carried out (Figs. $7 a$ and $7 b$ ). When compared to the shear response measured from the Iosipescu test, the shear behavior deduced from the off-axis test shows high stiffness and strength. This is because of the following: the off-axis tests are carried out under a multiaxial stress state and contain shear as well as other stress components when viewed in a local coordinate frame, whereas the simple shear tests (Iosipescu) have only a shear loading component present. In the off-axis tests, the behavior of the interface is controlled by transverse compression and shear, whereas in the Iosipescu test, the interface is subjected only to shear. Even though orthotropic plasticity theory suggests that the shear response can be extracted by specializing the plastic potential to a simple shear state, the mechanics of load transfer occurring through the fiber tow/matrix interface suggests otherwise, as reflected through the independent measurements (off-axis and Iosipescu) presented here. Thus, this shows an important result with respect to characterizing the shear behavior of interfaces. The results show that the true behavior of an interface is quite different under multiaxial stress states, and any attempt to extract the pure shear behavior of the interface from the multiaxial characterization will lead to error. Thus, the response of these composites must be characterized using two different protocols. One protocol should be used to extract the multiaxial behavior and another protocol should be used to extract the limiting case of pure shear.

\section{CONCLUDING REMARKS}

The off-axis compression test has been used to characterize the elastic-plastic response of unidirectional tow-reinforced stitched carbon fiber composites. A three-parameter yield function is used to capture the planar plastic response. The relationship between an appropriate orthotropic equivalent stress and a corresponding work-conjugate equivalent plastic strain has been established for static, quasi-static, and low-velocity impact loading conditions.

The values of $a_{11}, a_{12}$ and $a_{66}$ used for characterizing the equivalent stress-equivalent strain behavior show that $a_{66}$ and $a_{11}$ decreases and $a_{12}$ increases as the velocity of the impact increases. This can be attributed to the uniqueness of the microstructure of the specimen. This also shows that the $\sigma_{11}-\sigma_{22}$ coupling diminishes as the rate of loading is decreased. This implies diminished load transfer as the rate of loading increases, suggesting that the material response is indicative of a microstructure that appears to be "disintegrating" as the rate of loading is increased. This latter conclusion is further consolidated in a study on the mode I fracture energy of these composites (17).

As discussed earlier, the rate dependency in this type of composites is introduced because of the interface between carbon fiber tows and the vinyl ester matrix. Both the fibers and the matrix are rate-independent in the range of rates examined. The overall characterization (involving the biaxial stress state) of this type of composite shows a rate-dependent softening effect, whereas independently when they are subjected to single stress state conditions (such as simple shear Iosipescu tests), they show a rate dependency with hardening behavior. Thus, both tests (multiaxial as well as simple shear) are important to extract the true response of the material, and the lack of either of these will lead to erroneous results. Because of the presence of the fiber/ matrix interface and its rate dependency, the material is observed to soften as the rate of loading increases, contrary to behavior observed in metals, which show a hardening response.

\section{ACKNOWLEDGMENTS}

The authors wish to thank the DOE program management team and the Board and staff of the Automotive Composites Consortium, Energy Management Work Group. This work was sponsored by the Automotive Composites Consortium and the U.S. Department of Energy, Office of Transportation Technologies, Office of Advance Automotive Technologies, Lightweight Materials Program under Cooperative Agreement number DE-FC05-OR22910. The authors also wish to thank the Aerospace Engineering Department at the University of Michigan.

\section{REFERENCES}

1. C. T. Sun and J. L. Chen, Journal of Composite Materials, 23, 1009-1020 (1989).

2. D. Kenaga, F. J. Doyle, and C. T. Sun, Journal of Composite Materials, 21, 516-531 (1998). 
3. C. A. Weeks and C. T. Sun, Composites Science and Technology, 58, 603-611 (1998).

4. C. T. Sun and J. Tsai, Composites Science and Technology, 62, 1289-1297 (2002).

5. C. T. Sun and J. L. Chen, Journal of Composite Materials, 27, 1379-1390 (1993).

6. C. T. Sun and S. V. Thiruppukuzhi, Composites Part B, 29B, 535-546 (1998).

7. C. T. Sun and K. J. Yoon, Journal of Composite Materials, 26, 293-308 (1992).

8. C. T. Sun and K. J. Yoon, Journal of Composite Materials, 25, $1277-1296$ (1991).

9. C. T. Sun and T. S. Gates, AIAA Journal, 29, 457-463 (1991).

10. L. Ninan, J. Tsai, and C. T. Sun, International Journal of Impact Engineering, 25, 291-313 (2001).
11. H. M. Hsiao, I. M. Daniel, and R. D. Cordes, Journal of Composite Materials, 33, 1620-1642 (1999).

12. H. M. Hsiao and I. M. Daniel, Composites Part B, 29B, 523-533 (1998).

13. H. M. Hsiao, I. M. Daniel, and R. D. Cordes, "Dynamic Compressive Behavior of Thick Composite Materials. Experimental Mechanics," 38, 172-180 (1998).

14. Standard test methods for shear properties of composite materials by the v-notched beam method. Designation: ASTM D5379/D5379M-98.

15. A. Salvi, A. Waas, and A. Caliskan, Composites Science and Technology, 64, 83-97 (2004).

16. G. Odegard and M. Kumosa, Composites Science and Technology, 60, 2917-2943 (2000).

17. A. Salvi, J. Chung, A. Waas, and A. Caliskan, AIAA Journal, 41 (10), 2020-2028 (2003). 